\title{
Base Nacional Comum Curricular (BNCC): Sentidos em disputa na lógica das competências ${ }^{1}$
}

\author{
Luciana Nogueira ${ }^{2}$ \\ Juciele Pereira Dias ${ }^{3}$
}

All in all, you're just another brick in the wall (Pink Floyd, Another Brick in the Wall)

\begin{abstract}
Resumo: Filiadas à perspectiva teórico-metodológica da Análise de Discurso, analisamos o processo de produção de sentidos de 'competência', buscando compreender os modos de individuação do sujeito, na/pela língua, levando-se em conta o político, em uma formação social neoliberal significada, nesse caso, na discursividade do mercado-lógico. Ao lado dos efeitos de sentidos de 'competência', a questão do comum (unidade) e do diverso (diversidade) é o que norteia as análises do corpus, que é constituído por recortes do texto da Base Nacional Comum Curricular (BNCC - 2017).
\end{abstract}

Palavras-chave: Análise de Discurso. Político. BNCC. Competências.

\begin{abstract}
Affiliated to the theoretical-methodological perspective of Discourse Analysis, we analyze the process of producing of meanings of 'competence', seeking to understand the subject's modes of individuation, in / through the language, considering the political, in a neoliberal social formation meaning, in this case, in the the logical-market discursiveness. In addition to the effects of sense of 'competence', the question of the common (unity) and the diverse (diversity) is what guides the analysis of the corpus, which is constituted by cuts in the text of the National Curricular Common Base (BNCC - 2017).
\end{abstract}

Keywords: Discourse Analysis. Political. BNCC. Competencies.

\footnotetext{
${ }^{1}$ Uma primeira versão deste trabalho foi apresentado no Simpósio $X$ "O político-ideológico no ensino de língua(s)" do VIII Seminário de Estudos em Análise do Discurso (SEAD), realizado de 12 a 15 de setembro de 2017, em Recife - PE, na UFPE.

2 Docente do Programa de Pós-Graduação em Ciências da Linguagem, da Universidade do Vale do Sapucaí - Univás. Membro do Coletivo de Trabalho Discurso e Transformação - Contradit.

${ }^{3}$ Docente do Programa de Pós-Graduação em Ciências da Linguagem, da Universidade do Vale do Sapucaí - Univás. Membro do Coletivo de Trabalho Discurso e Transformação - Contradit.
} 
Résumé: Affiliés à la perspective théorico-méthodologique de l'Analyse du Discours, nous analysons le processus de production des significations de «compétences», cherchant à comprendre les modes d'individuation de l'individu, dans / à travers la langue, prenant en compte le politique, dans une formation sociale néolibérale signifiée, dans ce cas, dans le discours du marché-logique. En plus des effets de sens de «compétence», la question du commun (unité) et du divers (diversité) guide l'analyse du corpus, constitué par des coupures dans le texte de la Base Nationale Commun Curriculaire (BNCC - 2017).

Mots-clés: Analyse du Discours. Politique. BNCC. Compétences.

\section{Considerações iniciais}

Em diferentes circunstâncias sócio-históricas, os sentidos sobre Educação Básica são evidenciados nas políticas públicas, frequentemente denominadas por Reformas na Educação. Nos últimos anos, no Brasil, as (re)formas para a Educação tomaram diferentes formas: projetos como o "Escola Sem Partido"; o Decreto de Lei da Reforma do Ensino Médio; Seminários e as diferentes versões veiculadas da Base Nacional Comum Curricular (BNCC) da Educação Básica; atualizações das Leis da Educação a Distância (EaD), dentre outras. Os próprios sentidos de "Educação Básica" são ressignificados em relação às políticas públicas da Educação, pois, temos até 2013, e ainda hoje, os sentidos de "Educação Básica" produzindo um efeito de sinonímia de "Ensino Fundamental". Todavia, conforme estabelece as diretrizes e bases da educação nacional, pela Lei no 12.796, de 2013, “Educação Básica” passou a significar a “educação básica obrigatória e gratuita dos quatro aos dezessete anos de idade, organizada da seguinte forma: a) pré-escola; b) ensino fundamental; c) ensino médio. A questão da responsabilidade do Estado com a Educação Básica e gratuita como um direito de todos, garantida "inclusive para os que a ele não tiveram acesso na idade própria" ${ }^{4}$, é suprimido do Artigo $4^{\mathbf{o}}$ da Lei que institui os deveres do Estado com a Educação Escolar Pública em 2013.

\footnotetext{
${ }^{4}$ A questão da responsabilidade do Estado com a Educação Básica e gratuita como um direito de todos, garantida "inclusive para os que a ele não tiveram acesso-na idade própria", é suprimido do Artigo $4^{\circ}$ da Lei que garante os deveres do Estado com a Educação Escolar Pública (Cf. http://www.planalto.gov.br/ccivil 03/LEIS/I9394.htm, acesso em: 10 jul 2018).
} 
Nas políticas públicas, há sempre tentativas de recobrimento de sentidos, de se abarcar o 'todo' da sociedade, produzindo efeitos de unidade e de totalidade, todavia, conforme Mariani e Dias (2018), é impossível legislar sobre todas as práticas, pois há sempre um resto não significado, o real circunscreve a impossibilidade do tudo dizer no campo da linguagem. Nos perguntamos se estaria, assim, se produzindo uma tentativa de homogeneização das diferenças, da diversidade, denominada de 'diverso' e justificada como uma via para a construção da equidade/igualdade (unidade) denominada de 'comum'? Como são definidos os conhecimentos essenciais, aquilo que é comum e que deve ser ensinado? A partir de um encontro de pesquisas em desenvolvimento ${ }^{5}$, nós tomamos como objeto de análise o processo de produção de sentidos da institucionalização da BNCC, aprovada e publicada em dezembro de 2017. Tal documento é trabalhado por nós como uma política pública para a educação, em que entendemos os sentidos de 'público' em relação às diferentes tentativas de recobrimento desses sentidos, conforme Orlandi (2010).

Outra questão que se coloca para nós, a partir do que encontramos na BNCC, diz respeito aos modos de constituição do sujeito (jovem) na contemporaneidade, especificamente quando é individuado por instituições do Estado como a Escola. Assim, analisamos, na perspectiva discursiva, a constituição do sujeito “autoempreendedor" (NOGUEIRA, 2017) em relação a documentos norteadores de práticas educacionais no Brasil. Consideramos que os discursos sobre o (mercado de) trabalho e sobre as relações de trabalho afetam a constituição desse sujeito colocado como “autoempreendedor", em tentativas de regular 'como' e 'o que' se pode e deve ser estudado na escola, produzindo um jogo político nas relações Língua-Estado-Nação e, por sua vez, seus efeitos nos discursos sobre educação e ensino em reforma políticaeducacional ${ }^{6}$. O corpus de análise, portanto, é constituído de recortes do texto da

\footnotetext{
${ }^{5}$ Nos referimos a orientações de trabalhos de dissertação e de tese, bem como atividades em projeto de pesquisa em acordo interinstitucional, trabalhos vinculados a Grupos de Pesquisas e a projeto de extensão.

${ }^{6}$ Sobre o como e o que se pode ser ensinado na Escola, o professor Antonio Carlos Amorim, da Faculdade de Educação da Unicamp, em entrevista ao jornal da Unicamp, afirmou que: "A Base estabelece, por exemplo, que a alfabetização ocorra de forma mais precoce. Assim, a educação infantil se estruturaria dentro das lógicas da escolarização, para a qual a constituição de um currículo orientador é uma das bases fundamentais. O documento também confere ênfase a determinadas disciplinas que considera prioritárias, em detrimento de outras. Um dos interesses em foco são os
} 
terceira versão da BNCC (publicada em abril de 2017) em relação a discursos outros em que possíveis relações entre Educação e Trabalho são evidenciadas, como as que "preparam os alunos para o mercado de trabalho", de modo a atender a demanda do (mercado de) trabalho. No entanto, essa demanda é de quem para quem? De que maneira esse Aparelho Ideológico de Estado, que é a Escola, pode servir para a reprodução do mercado-lógico na contemporaneidade?

A partir de alguns estudos realizados por nós sobre o que se tem produzido na discursividade da BNCC, retomamos Kuenzer (2017) que, ao tratar do tema controverso da relação entre rigidez e flexibilidade no ensino, na Educação formal - para tratar da reforma do ensino médio ${ }^{7}$ - aponta que os sentidos de flexibilização não colocam em evidência que as relações entre capacitação e trabalho são projetadas enquanto utilização das novas tecnologias, discurso no qual os sentidos de competências são determinados por desconhecimentos de automação industrial, do conhecimento do trabalho em uma lógica binária articulada e reduzida ao funcionamento de uma lógica do mercado de trabalho. Uma discursividade mercado-lógica em que, em um movimento circular, os sentidos de capacitação para o (mercado de) trabalho, por sua vez, de acordo com Kuenzer (2017, p. 340), venham a "reger-se pela lógica dos arranjos flexíveis de competências diferenciadas", bem como venham a reger essa lógica das competências em forma de retorno ao mercado, acrescentamos.

Vale dizer, a respeito do processo de elaboração da BNCC, que as últimas versões do texto não foram amplamente discutidas com a sociedade e houve e há resistência a essa proposta. Em nome de um discurso da flexibilidade, fortemente presente no projeto de reforma do ensino médio e também na BNCC, pela abordagem

rankings internacionais que avaliariam a qualidade da educação. O objetivo parece ser, em suma, gestar formas de melhorar a imagem do país no plano internacional”. (JORNAL DA UNICAMP, 04 dez 2017).

7 Segundo a autora, "Sob a justificativa da flexibilização das trajetórias curriculares para atender aos projetos de vida dos jovens, a organização curricular passa a admitir diferentes percursos. Assim, da carga horária total, no máximo 1.800 horas serão comuns, atendendo à Base Nacional Comum Curricular (BNCC) e incluindo a parte diversificada prevista no art. 26 da Lei n 9394/1996; o art. 35 da Lei máxima do conteúdo curricular comum, "de acordo com a definição dos sistemas de ensino". Isso pode significar autonomia dos sistemas de ensino para propor uma carga horária menor, uma vez que a Lei não estabelece o mínimo. A carga horária de componentes curriculares comuns corresponde a dois terços de um percurso de 3 anos com 800 horas por ano e a $60 \%$ de um percurso de 3 anos com 1.000 horas por ano; caso o percurso seja integral, com 1.400 horas por ano em 3 anos, o conteúdo comum corresponderá a $38 \%$ do total do curso, ou seja, pouco mais que um terço" (KUENZER, 2017, p. 334). 
por competências, estaria assim, num outro polo, colocando a rigidez ao educador, que deveria seguir manuais e aplicar técnicas e avaliar conjuntos de competências. E assim questionamos sobre o modo como se darão essas avaliações. Que padrão é esse que se quer validar como diretriz para a educação, para os processos de ensino no Brasil?

Os sentidos se inscrevem, desse modo, na discursividade da BNCC, sobre a qual buscamos compreender como se dão as relações de sustentação ou de reafirmação de um discurso como esse e não outro, que coloca o educador em outro lugar. Segundo a docente da Faculdade de Educação da Unicamp, Maria do Carmo Martins, em matéria para o jornal da Unicamp sobre a BNCC, temos que:

\footnotetext{
A Base não é uma pauta específica dos segmentos privatizantes. Ao contrário, ela está na agenda de diferentes grupos sociais, inclusive os que fazem uma forte defesa da escola pública de qualidade. No entanto, os representantes dos interesses mercadológicos se vincularam ao Estado e conseguiram explicitar suas demandas (JORNAL DA UNICAMP, o4 dez 2017, s/p.).
}

Desse modo, considerando os sentidos em disputa na BNCC, é preciso salientar as condições sócio-históricas de produção desse discurso. Kuenzer (2017) trata do que ela denomina de pedagogia da acumulação flexível, para sua análise da reforma do ensino médio, mostrando como há uma base material do regime de acumulação flexível que produz uma demanda, a qual deve ser assumida pelo Estado. A pedagogia da acumulação flexível estaria respondendo a essa demanda, segundo a autora. Portanto, o modo conflituoso e antidemocrático em que o processo de construção dessas políticas públicas vêm se dando, atestando a presença do político, sobretudo nessa articulação entre os setores privados e o Estado (que regula o social), "atestam a força das bases materiais na estruturação das políticas públicas na acumulação flexível" (KUENZER, 2017, p. 342).

Por outro lado, sustentando tais sentidos na discursividade mercado-lógica, a da lógica binária, a do digital, das tecnologias do contemporâneo, é determinante de um efeito de pré-construído de que para se produzir conhecimento e ao mesmo tempo condições para a constituição do sujeito na Escola, na atualidade, é necessário trabalhar com e sobre tecnologias (digitais). Dito de outro modo, de um lado, as tecnologias audiovisuais, imagéticas, sonoras, os hiperlinks e dispositivos móveis se 
colocam como evidências de "facilidades" para o ensino e para a Educação a Distância (EaD) encurtando distâncias e ganhando tempo, ou seja: ganhar tempo para aumentar a velocidade da roda que "patinha em regras estéreis" em meio ao processo de (re)produção mercado-lógico capitalista, neoliberal. Patinhar ${ }^{8}$ na repetição ou abrir-se ao desafio de deslizar? Um deslizamento de sentidos livres, soltos na cadeia significante (du n’importe quoi), liberados de relações ou retornos ou deslocar-se na rede de relações de sentidos, de um sentido (im)posto que se abre para a possibilidade do sentido outro, de pensar por si mesmo e produzir o diferente? (MARIANI e DIAS, 2018). É de encontro a esses sentidos que estamos trabalhando sobre o modo como a discursividade do mercado-lógico, impulsionada pela tecnologia (máquina, digital), determina o processo de produção de sentidos na/da BNCC.

\section{O sujeito, a língua e o político na $\mathrm{BNCC}$}

A questão da constituição do sujeito "autoempreendedor" nos colocou a refletir sobre a presença e os sentidos da palavra 'empresa'. Assim, vimos que a palavra empresa vem do italiano "impresa" que significa: "atividade a que uma pessoa se dedica”. Do latim emprehendere, formado por EM-, 'em', mais PREHENDERE, "pegar, capturar, levar diante de si, segurar”. Outros derivados da palavra são 'empreendedor' e 'empreendedorismo"' 9 . Desse modo, em um batimento entre descrição e interpretação, temos, no processo de constituição do sujeito em relação à empresa (pegar, capturar, segurar), os sentidos de ordem mercado-lógica (capacitar, patinhar) e de escola/escolarização (formação, conhecimento) inscritos na discursividade da BNCC.

\footnotetext{
${ }^{8}$ Expressão de Mattoso Câmara (1956) sobre a relação entre a gramática escolar, que patinha em regras estéreis, mesmo em relação com a Filologia. Patinhar, em nossa leitura a partir do dicionário Aurélio, é o movimento de bater, agitar ou remexer a água ou a lama com os pés, mas sem sair do lugar, apesar de ter as rodas a rodar. Segundo o léxico: dicionário de português online, patinhar é "Agitar a água, como fazem os patos num tanque ou numa corrente. [...] Diz-se da máquina de comboio, quando as rodas giram, sem que a máquina ande".

${ }^{9}$ Consultamos 0 site "Origem da Palavra", disponível em: (http://origemdapalavra.com.br/site/pergunta/origem-da-palavra-empresa/). Acesso em: 29/09/2017.
} 
Pensamos, então, no modo como se dá a constituição do sujeito “autoempreendedor" (DARDOT e LAVAL, 2009; NOGUEIRA, 2017) nas políticas públicas de ensino e nas políticas linguísticas de documentos norteadores de práticas educacionais no Brasil, no caso a BNCC e, sobretudo, buscando compreender os modos de individuação (ORLANDI, 2012) desse sujeito, na/pela língua, em uma "Sociedade Neoliberal" (DARDOT e LAVAL, 2009). Estamos, assim, problematizando as maneiras como a Educação está se constituindo em uma articulação mais direta com o mercado e suas regras de competitividade internacionais, sendo o Estado o legitimador dessa articulação. Considerando isto, pensamos, com Pfeiffer (2010, p. 86), que "o vínculo construído de 'modo natural' entre o ensino e o trabalho é regularmente produzido, por meio das leis, das políticas de modo mais geral e pelas teorias que ascendem e acenam ao Estado".

Considerando isto, uma questão que fundamenta teoricamente este trabalho é pensar o lugar do político, no sentido em que este vem sendo deslocado para outro lugar (NOGUEIRA, 2017). A análise da textualização do político se dá em gestos de interpretação inscritos na materialidade do texto. $\mathrm{O}$ político, compreendido discursivamente, significa que o sentido é sempre dividido e essa divisão tem uma direção que é afetada pelas relações de força derivadas da forma da sociedade na história (ORLANDI, 1998). O político pode ser entendido como conflito, a partir das posições sujeito que são assumidas. Portanto, quando falamos em deslocamento do lugar do político, estamos tratando de um efeito ideológico. Isto é, estamos dizendo que há um apagamento daquilo que é constitutivo das relações de classe no capitalismo.

Desse modo, os discursos sobre o (mercado de) trabalho e sobre as relações de trabalho afetam a constituição desse sujeito "autoempreendedor", em tentativas de regular o que se pode e deve ser estudado na escola, por meio de uma abordagem por “competências”, colocando em jogo as relações Língua-Estado-Nação enquanto recobertas por certo funcionamento ideológico do consenso na contemporaneidade e, por sua vez, seus efeitos nos discursos sobre educação e ensino em reforma políticaeducacional. Continuando o diálogo com Pfeiffer, para nós aqui também interessa ver 
o modo como certo conhecimento científico é apropriado pelo Estado, "seja na forma de política governamental, seja na forma de organizações não governamentais que trabalham na estabilização de um (uns) Estado (Estados)" (PFEIFFER, 2010, p. 87).

Esse processo de produção de sentidos e de constituição do sujeito, especificamente, nos remete ao funcionamento da "língua de algodão" , própria do neoliberalismo, a nosso $\operatorname{ver}^{10}$ e que pode tomar uma forma outra quando posta em relação aos sentidos de "língua metálica" (GADET e PÊCHEUX, [1981] 2010), essa da maquinaria, da tecnologia". Para contrapor a noção de "língua de madeira" (aquela pela qual se produzem estereótipos e repetições na linguagem dos políticos sustentados/escondidos atrás de formulações prontas, usadas por líderes do movimento operário em declínio), Lecercle (2004) diz que o discurso político burguês prefere a "língua de algodão" ("la langue de coton"), que também é estereotipada e repetitiva como a outra, bem como permite uma "mundialização do non-sens". Ao retomar a definição de "língua de algodão" de Huyghe (1991), ele a define como a língua que tem resposta para tudo porque ela não enuncia nada. É uma língua de poder, consensual por excelência. O autor se volta então para a descrição linguística de Marie-Dominique Perrot sobre essa língua, em seu artigo "Mondialisation du non-sens" (2002), em que analisa uma brochura da ONU (Organização das Nações Unidas), publicada em 2000 em Genebra: Um mundo melhor para todos ${ }^{\mathbf{2}}$.

Com isso, ele aponta que a língua do consenso não é transparente, pois ela tem uma materialidade e uma especificidade. De um lado, podemos pensar nas características semânticas concernidas à construção do consenso segundo o princípio: "nenhum sentido, nenhuma vagueza” (“nul sens, nulle vague”) (LECERCLE, 2004). Daí

\footnotetext{
${ }^{10}$ Em outro momento, a noção de língua de algodão, como própria do neoliberalismo, foi pensada para analisar o funcionamento do discurso de gestão empresarial (NOGUEIRA, 2015; 2016; 2017), bem como foi retomada no estágio pós-doutoral, trabalhada em um alargamento desse discurso de gestão, nas práticas (políticas) voltadas à Educação e às Instituições, de um modo mais geral. Os trabalhos em torno dessa questão foram apresentados em dois eventos com os títulos: O Discurso de Gestão e a Constituição do Sujeito Autoempreendedor: reflexões sobre a relação Educação e Trabalho", na Abralin 2017, na UFF; e "Discurso, Sujeito e Relações de Trabalho: a constituição do sujeito autoempreendedor", no $4^{\circ}$ Simdt, em 2016, na Univás.

${ }^{11}$ A noção de "língua metálica", de Pêcheux e Gadet, na relação com as máquinas, retomando a discussão de Barthes em relação aos sentidos de automação na atualidade, foi discutida em "Dizeres musicalizados em movimentos da sociedade" (DIAS, no prelo) e que foi ressignificada na relação com "língua de algodão" nesta pesquisa.

${ }^{12}$ Negritados nossos.
} 
a sensação de perda de sentido e a prevalência de bons sentimentos, segundo o autor, pois, quem, de fato, iria encontrar a falha com a perspectiva de um "mundo melhor para todos"? Quem poderia, seriamente, declarar oposição aos direitos humanos, à paz ou elogiar a pobreza? Essas perguntas são colocadas por Lecercle (Ibid., p. 201) como algo óbvio, mas muito geral: o léxico do consenso apaga, ou seja, ignora deliberadamente os problemas econômicos, sociais e políticos, ao mesmo tempo que promete resolvê-los. É, por exemplo, o que podemos ler no enunciado a seguir, do texto da BNCC: "A equidade supõe a igualdade de oportunidades para ingressar, permanecer e aprender na escola, por meio do estabelecimento de um patamar de aprendizagem e desenvolvimento a que todos têm direito" (BNCC, 2017, p. 11, negritados nossos).

Na definição de "língua metálica", daquela "língua" não natural, da maquinaria, Gadet e Pêcheux ([1981] 2010), ao retomarem Barthes ([1978] 2007), dizem que se há uma língua fascista, é a língua metálica, que não funciona pela censura/repressão explícita e sim pela imposição de que se diga $x$, se faça $x$. Trata-se de uma língua pela qual se produzem formas ou fórmulas linguísticas que colocam certos enunciados em evidenciamento em prol do apagamento de outros, como um acelera-dor, otimiza-dor, pro-pagador do nonsense produzido pela "língua de algodão" no processo de gestão de sentidos em uma sociedade neoliberal. Nesse sentido, cada vez mais temos a ilusão das máquinas nos abrirem a possibilidade de estabelecer relações antes não possíveis, mas também cada vez mais somos obrigados a preencher (dizer) documentos on-line de uma maneira unificada/universalizada, em que só pode ser feito daquela maneira e não de outra na máquina (Por exemplo: Declaração da Receita Federal, agendamento para confecção ou renovação de documentos, atividades objetivas on-line em ambientes virtuais de aprendizagem-AVA, etc.).

Compreendemos, assim, como as línguas naturais são capazes de política e de recobrimento do político, bem como a relação com a máquina, com a língua metálica, esse funcionamento é afetado. A língua de algodão caracterizaria, assim, o funcionamento paradoxal de que ao mesmo tempo em que se tem um esvaziamento de sentidos, se tem uma saturação de sentidos (NOGUEIRA, 2017). Trata-se da 
maleabilidade da língua, do discurso, do algodão, que é macio, que absorve e é usado tanto para anestesiar como para tapar o ouvido, é o acessório indispensável da maquiagem, já que protege e suaviza, conforme descreve Huyghe (1991).

\section{O comum (unidade) e o diverso (diversidade) na BNCC}

O arquivo desta pesquisa sobre a BNCC é constituído por gestos de leitura de diferentes versões (textos) do documento, publicadas em 2017, bem como discursos sobre a BNCC, seja o discurso midiático, crítico, em circulação ou produções acadêmicas de diferentes campos do saber. Na produção do presente estudo, o corpus de análise tomou forma com recortes de fragmentos do texto da BNCC, em que são definidos os conceitos fundantes da Base Nacional Comum Curricular e como ela é formada pelo/para o "desenvolvimento de competências". Cabe salientar que esses recortes estão presentes tanto na terceira versão da BNCC, publicada em abril de 2017, quanto em sua versão final para a Educação Infantil e Ensino Fundamental, publicada em dezembro de 2017 e na versão da BNCC para o Ensino Médio, publicada em abril de 2018. Apresentamos, a seguir, os recortes (R) estabelecidos por nós, para análise:

R1 - [...] a LDB deixa claros dois conceitos decisivos para todo o desenvolvimento da questão curricular no Brasil. O primeiro, já antecipado pela Constituição, estabelece a relação entre o que é básico-comum e o que é diverso em matéria curricular: as competências e diretrizes são comuns, os currículos são diversos. O segundo se refere ao foco do currículo. Ao dizer que os conteúdos curriculares estão a serviço do desenvolvimento de competências, a LDB orienta para a definição das aprendizagens essenciais, e não apenas dos conteúdos mínimos a serem ensinados. Essas são duas noções fundantes da BNCC. (BNCC, 2017, p. 09, negritados nossos). 
A seguir, uma figura que produzimos para descrever de outro modo o jogo político das palavras na definição do desenvolvimento de competências na BNCC.

Figura 1: Discurso transverso da LDB

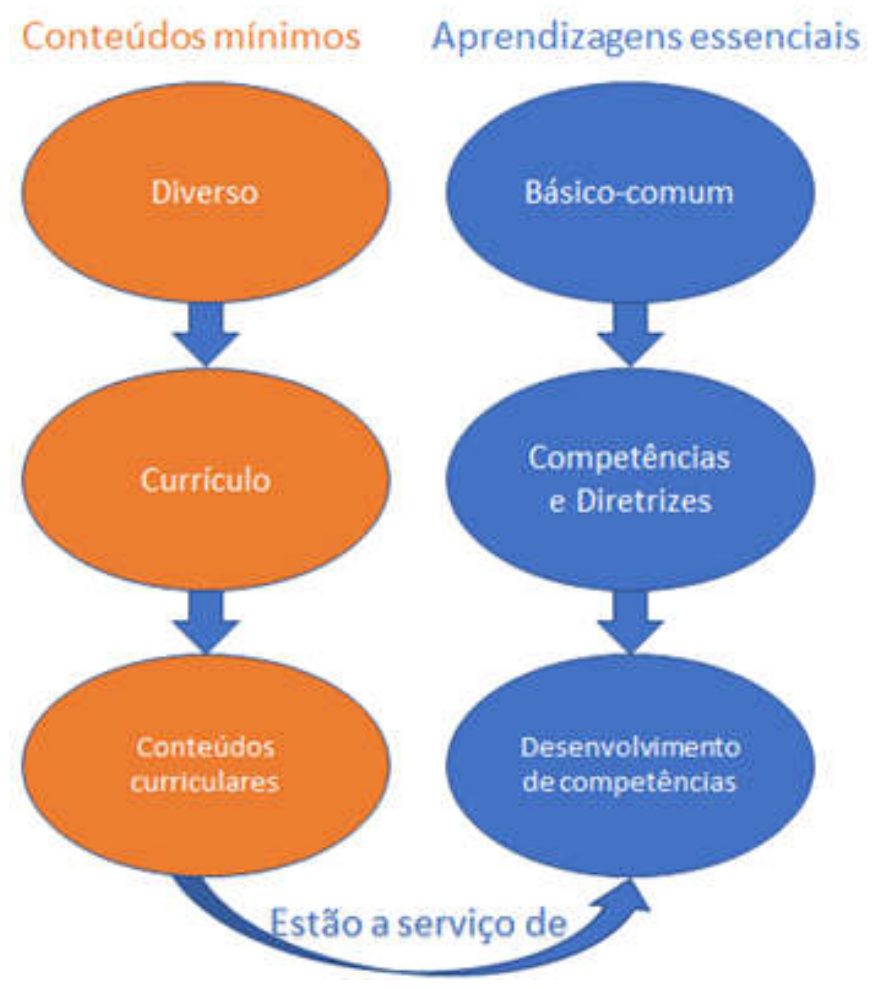

Fonte: elaborado pelas autoras

Na textualidade do R1, temos duas noções colocadas como fundantes da BNCC, que se inscrevem por um atravessamento do discurso da Lei n. 9.394 de $1996^{13}$, que estabelece as diretrizes e bases da educação nacional, ou seja, a LDB. As duas noções “aprendizagens essenciais" e "conteúdos mínimos" são reescritas no Ri por um jogo

\footnotetext{
${ }^{13}$ Cabe salientar a constante atualização da LDB nos últimos anos, sendo a última no dia 16 de maio de 2018. Fonte: http://www.planalto.gov.br/ccivil 03/ Ato2015-2018/2018/Lei/L13666.htm\#art1, acesso em 17 jul 2018.
} 
binário de palavras (básico-comum/diverso, competências e diretrizes/currículo, desenvolvimento de competências/conteúdos curriculares) que convergem para o enunciado "estão à serviço do desenvolvimento de competências". Temos no processo de institucionalização da BNCC um jogo de forças e de sentidos com o que é (re)escrito na LDB e na Constituição ${ }^{14}$, bem como, no R1, há um jogo de palavras entre "conceito" e “noção" nos enunciados:

E1: "a LDB deixa claros dois conceitos decisivos para todo o desenvolvimento da questão curricular no Brasil”;

E2: "a LDB orienta para a definição das aprendizagens essenciais, e não apenas dos conteúdos mínimos a ser ensinados. Essas são duas noções fundantes da BNCC".

No primeiro enunciado, temos que há dois conceitos decisivos que parece apontar para a questão curricular ou do que é diverso, entretanto, no segundo enunciado a questão dos conteúdos mínimos se faz presente pela denegação, em que o substantivo "conteúdo" é adjetivado por "mínimo" ao ser presentificado como uma noção fundante da BNCC. Vejamos, a seguir, o R2.

$\mathbf{R 2}$ - A relação entre o que é básico-comum e o que é diverso é retomada no Artigo 26 da LDB, que determina que: 'os currículos da Educação Infantil, do Ensino Fundamental e do Ensino Médio devem ter base nacional comum, a ser complementada, em cada sistema de ensino e em cada estabelecimento escolar, por uma parte diversificada, exigida pelas características regionais e

\footnotetext{
${ }^{14}$ De acordo com o Art. 22 da Constituição, "Compete privativamente à União legislar sobre" " XXIV diretrizes e bases da educação nacional". http://www2.camara.leg.br/legin/fed/consti/1988/constituicao-1988-5-outubro-1988-322142publicacaooriginal-1-pl.html. Acesso em 17 jul 2018.
} 
locais da sociedade, da cultura, da economia e dos educandos' ${ }^{15}$ (BRASIL, 1996; ênfase adicionada)' (BNCC, 2017, p. 10, negritados nossos).

Na materialidade do título da BNCC em relação aos recortes 1 e 2 é produzido um deslizamento de sentidos de "Base-comum" do texto da BNCC para "Base Nacional Comum, a ser complementada" do texto da LDB (cf. Lei 12.796 de 2013). Nesse deslizamento, há a atualização da palavra "Nacional" que coloca em cena um discurso outro, em potencial, que faz ressoar sentidos de "Internacional", do que é comum para além do "Nacional" e pode ser representado por (documentos de) organizações internacionais como a Organização para a Cooperação e Desenvolvimento Econômico $(\mathrm{OCDE})^{16}$ e a Organização das Nações Unidas para a Educação, a Ciência e a Cultura (Unesco). Nesse movimento, em uma deriva de sentidos, irrompe na textualidade da BNCC a palavra "Nacional" por uma relação a Internacional, o que nos faz remontar do título da BNCC a palavra "Curricular", posta como da ordem do "diverso", do que está "à serviço de" o que é comum (ou Internacional?). De outro lado, da Lei de 2013, temos que a educação básica deve ter "base nacional comum a ser complementada" conforme o que é exigido pelas "características regionais e locais da sociedade, da cultura, da economia e dos educandos". Nesse caso, como funciona a tensão entre o que é comum nacional (internacional) e o que é exigido pelo "diverso" do regional e do local? Quais são os parâmetros nacionais para se determinar o que é o "comum"? E o que é regional e local é colocado em separado?

A seguir, temos mais dois recortes correlacionados, relativos à definição da proposta da BNCC. Vejamos:

R3 - A equidade reconhece, aprecia e os padrões de sociabilidade das várias culturas que são parte da identidade brasileira [sic]. Compreende que todos são

\footnotetext{
15 Inscrito na LDB a partir da Lei 12.796 de 4 de abril de 2013, disponível em http://www.planalto.gov.br/ccivil 03/ Ato2011-2014/2013/Lei/L12796.htm\#art1, acesso em 17 jul 2018.

${ }^{16} \mathrm{Em} 30$ de maio de 2017, o governo brasileiro formalizou pedido de entrada na OCDE, também conhecida como "Grupo dos ricos" desde 2007. Disponível em: http://www2.planalto.gov.br/acompanhe-planalto/releases/2017/05/governo-brasileiro-formalizapedido-para-entrar-na-ocde, acesso m 17 jul 2018.
} 
diversos, que a diversidade é inerente ao conjunto dos alunos, inclusive no que diz respeito às experiências que trazem para o ambiente escolar e aos modos como aprendem (BNCC, 2017, p. 11, negritados nossos).

R4 - A equidade supõe a igualdade de oportunidades para ingressar, permanecer e aprender na escola, por meio do estabelecimento de um patamar de aprendizagem e desenvolvimento a que todos têm direito. Decorre disso a necessidade de definir, mediante pactuação interfederativa, direitos e objetivos de aprendizagem essenciais a ser alcançados por todos os alunos da educação básica. A BNCC vem cumprir esse papel, tendo como foco principal a igualdade e a unidade nacional (BNCC, 2017, p. 11, negritados nossos).

O R3 e o R4 são abertos por uma definição de equidade na BNCC. No R3, temos a "equidade" em relação ao reconhecimento e apreciação de padrões de sociabilidade de várias culturas que são parte da identidade brasileira. Há uma quantificação de culturas marcada pelo "várias" e uma indefinição do que são "padrões de sociabilidade" na perspectiva da BNCC. E a seguir, é colocado que a "equidade" compreende que todos são diversos e que a diversidade é inerente ao conjunto dos alunos, o que conduz da quantificação indefinida para uma quantificação marcada pelo efeito de totalidade, por "todos são diversos".

No R4, temos que "a equidade supõe a igualdade de oportunidades para ingressar, permanecer e aprender na escola, por meio do estabelecimento de um patamar de aprendizagem e desenvolvimento a que todos têm direito", o que novamente coloca o efeito de totalidade em cena, pelo enunciado "todos têm direito", mas o que questionamos é como se dá o estabelecimento desse patamar de aprendizagem e desenvolvimento? Uma possível resposta é posta no sentido de que esse patamar se daria por "pactuação interfederativa”, o qual a BNCC deve cumprir ao ter "como foco principal a igualdade e a unidade nacional". 
Como isso fica em relação à abordagem por competências? Nesse sentido, Silva (2017), retomando a formulação de Gadet e Pêcheux (2004) de que a questão da língua é uma questão de Estado, afirma que:

As políticas públicas de escolarização nos permitem, pois, observar o modo como o Estado trabalha as relações entre a unidade e a diversidade, o universal e o local, determinando um conjunto de práticas em diferentes instituições, mas antes e, sobretudo, na Escola (SILVA, 2017, p. 317).

Então, entendemos que, por meio da BNCC, que é uma política pública para a Escola/Educação, faz-se a política justamente apagando ela, nos termos em que Pêcheux e Gadet (1998, s/p.) trata desse apagamento: "A tendência logicista nega a política falando aparentemente de outra coisa, enquanto a tendência sociologista recalca a política falando ou acreditando falar dela". Conforme as análises que realizamos, trata-se aqui desta segunda tendência, em relação ao mercado-lógico e em relação ao político ser deslocado do lugar que the seria próprio, como vimos acima.

Retomando o foco principal da BNCC e correlacionando os recortes anteriores, temos que se "todos são diversos" e o que é "diverso" está "à serviço da" "base-comum", então teríamos que "todos estão à serviço da base-comum", de modo que a "diversidade" do "diverso" fica recoberta pelo que é da ordem do "comum", da competência em relação ao que se tem denominado "igualdade". Nos recortes, os sentidos de igualdade estão definidos como oportunidades de ingressar, de permanecer e de aprender na escola e por sentidos de direito de todos à aprendizagem, ao desenvolvimento de um determinado patamar. Trata-se de um jogo político de palavras, cíclico, em que o que é posto como "comum" não é definido à serviço do que é "comum" (internacional?) na diversidade brasileira, por exemplo. Esse "comum" é posto como aprendizagem ou competência, aquela que deve ser alcançada na educação básica para ser replicada.

A seguir, pelo atravessamento do discurso da LDB, temos dois recortes definidores de competências no texto da BNCC: 
R5 - Segundo a LDB (Artigos 32 e 35), na educação formal, os resultados das aprendizagens precisam se expressar e se apresentar como sendo a possibilidade de utilizar o conhecimento em situações que requerem aplicá-lo para tomar decisões pertinentes. A esse conhecimento mobilizado, operado e aplicado em situação se dá o nome de competência (BNCC, 2017, p. 15, negritados nossos).

R6 - Aprender a aprender, saber lidar com a informação cada vez mais disponível, atuar com discernimento e responsabilidade nos contextos das culturas digitais, aplicar conhecimentos para resolver problemas, ter autonomia para tomar decisões, ser proativo para identificar os dados de uma situação e buscar soluções, são competências que se contrapõem à concepção de conhecimento desinteressado e erudito entendido como fim em si mesmo (BNCC, 2017, p. 17, negritados nossos).

No R5 temos que "competência" é definida como o "conhecimento útil", "mobilizado", “operado" e "aplicado” em situações que "requerem aplicá-lo" para tomar “decisões pertinentes”. A competência, nessa perspectiva, seria um conhecimento aplicado. A noção de conhecimento aplicado escolar é colocada em relação ao sujeito, de modo que "ser competente", "ser capaz de", se reduz a saber ativar e utilizar um conhecimento construído. E, por fim, no R6, parece-nos que "competências", predicada como conhecimento aplicado, interessado, se opõe a "conhecimento desinteressado", predicado como conhecimento erudito, o qual é posto tendo como fim apenas si mesmo. Perguntamos: Em relação a que esse conhecimento é desinteressado no jogo de forças da competitividade mercado-lógica? Nesse sentido, retomamos as palavras de Mariza Vieira da Silva (2018):

O que chama a nossa atenção é a noção de conhecimento, que pode ser discutida em relação a outros elementos não ditos como "informação", "reconhecimento". A BNCC toma o conhecimento como uma racionalidade instrumental, naturalmente objetivo e neutro, mobilizado como algo pronto, acabado, capaz de ser aplicado, ativado, utilizado por um sujeito intencional e consciente capaz de dominá-lo e controlá-lo. Um conhecimento transparente, 
sem equívocos, em situação de uso, de comunicação como ação individual na solução de problemas coletivos, sociais (SILVA, 2018, p. 112).

O "aprender a aprender", o "discernimento e a responsabilidade" (sobretudo no digital), "aplicar conhecimento na resolução de problemas", "autonomia para tomar decisões", "ser proativo e buscar soluções" no R6 dá visibilidade, textualmente, a essa discursividade que se abriga numa formação discursiva neoliberal em que se constitui esse sujeito "autoempreendedor" - o que deve ser empreendedor de si mesmo - de maneira que a subjetividade é gerida para assegurar o processo de assujeitamento, historicamente atualizado, conforme Pêcheux (2011), a partir de um jogo político de liberdade e submissão.

Diferente do que se denomina enquanto um processo de democratização ou de redemocratização do ensino pela promoção da igualdade e da unidade nacional, estamos assistindo a um processo de (re)massificação nas políticas públicas de ensino de uma sociedade neoliberal mercado-lógica em que as artes mecânicas passam a ser artes automatizadas e os sujeitos do conhecimento individualizados enquanto usuários do conhecimento (tomado enquanto informação) capacitados para operar x atividade.

Compreendendo o político, na/pela língua, enquanto divisão dos sentidos em disputa, a partir de Pfeiffer (2010), problematizamos como as políticas de ensino se estruturam sob o mesmo funcionamento que sustenta as políticas públicas em relação ao discurso da "capacidade de adaptação", uma prática consensual determinante da nossa sociedade neoliberal atual e que se liga ao discurso da acumulação flexível como vimos em Kuenzer (2017), aos sentidos de fluido, efêmero, fugidio e portanto é preciso estar "preparado" (já na Escola) para lidar com essa flexibilidade, daí os sujeitos devem ter (ser?) um conjunto de competências, conforme a demanda. Há uma lista de 10 competências que a BNCC apresenta e aqui chamamos a atenção para a competência de número 10:

"Agir pessoal e coletivamente com autonomia, responsabilidade, flexibilidade, resiliência e determinação, tomando decisões, com base nos 
conhecimentos construídos na escola, segundo princípios éticos democráticos, inclusivos, sustentáveis e solidários" (BNCC, 2017, p. 18-19, grifos nossos).

Novamente temos esse conjunto de palavras (destacadas em negrito) em relação, funcionando para o processo de interpelação/constituição do sujeito (livre e responsável), conforme vimos logo acima, determinando os sentidos dessa proposta de política pública que é a BNCC.

Orlandi (2014) salienta que nem o sentido de público, nem os sentidos das políticas públicas são evidentes quando tomados na perspectiva discursiva, considerando que as disputas de sentidos são desiguais e com dominância, permeadas de tentativas de recobrimento das significações, o que nos leva ao questionamento sobre a constituição do sujeito em/por essas políticas. Não há dominação sem resistência, segundo Pêcheux ([1978] 1995), e um lugar possível de resistência se constitui em uma prática de análise discursiva desse tornado de políticas públicas que se pretendem "reformistas”, em especial as políticas públicas que colocam em relação, direta ou indiretamente, Educação e Trabalho, que se sustentam em uma discursividade da crise econômica, das evidências postas de uma necessidade de recuperação do mercado brasileiro, por exemplo.

Por fim, apresentamos mais dois recortes nos quais podemos ver a ocorrência das palavras "competência” e "habilidade” combinadas, numa coordenação:

R7 - (Nota 19): Segundo a pesquisa elaborada pelo Cenpec, das 16 Unidades da Federação cujos documentos curriculares foram analisados, 10 delas explicitam uma visão de ensino por competências, recorrendo aos termos "competência" e "habilidade" (ou equivalentes, como "capacidade", "expectativa de aprendizagem" ou "o que os alunos devem aprender"). "O ensino por competências aparece mais claramente derivado dos PCN porque eles são o primeiro documento nacional no País que explicita e detalha as competências (desdobradas em habilidades) a ser adquiridas pelos alunos em todas as áreas de conhecimento" (p. 74). CENPEC - Centro de Estudos e Pesquisas em Educação, Cultura e Ação Comunitária. Currículos para os anos finais do Ensino 
Fundamental: concepções, modos de implantação e usos. São Paulo: Cenpec, 2015 (BNCC, 2017, p. 16).

No R7 temos uma maneira de se definir os significantes "competência" e "habilidade" em relação à sua história no ensino, indicando também o que se considera como seus equivalentes: "capacidade", "expectativa de aprendizagem" e "o que os alunos devem aprender".

R8 - No Brasil, essas referências legais têm orientado a maioria dos Estados e Municípios na construção de seus currículos [nota 19]. Essa mesma tendência de elaboração de currículos referenciados em competências é verificada em grande parte das reformas curriculares que vêm ocorrendo em diferentes países desde as décadas finais do século XX e ao longo deste início do século XXI [nota 2o]. É esse também o enfoque adotado nas avaliações internacionais da Organização para a Cooperação e Desenvolvimento Econômico (OCDE), que coordena o Programa Internacional de Avaliação de Alunos (Pisa, na sigla em inglês), e da Organização das Nações Unidas para a Educação, a Ciência e a Cultura (Unesco, na sigla em inglês), que instituiu o Laboratório Latino-americano de Avaliação da Qualidade da Educação para a América Latina (LLECE, na sigla em espanhol) (BNCC, 2017, p. 16).

No R8 temos as indicações do processo de elaboração dos currículos enquanto competências, em que se coloca em evidência uma integração de Estados e de Municípios em relação à história das reformas de ensino, bem como coloca uma integração de organizações internacionais no sentido de produzir o efeito de validação/legitimidade ao documento em formulação.

\section{Considerações finais}


A língua é a competência em si. E o que é mais, é verdade.

Não somos competentes em nenhuma outra coisa.

Lacan, Seminário 18

O que estamos colocando em questão é esse discurso do modelo das competências, de uma abordagem por competências, que implica, de certo modo, em avaliar sistematicamente as "competências adquiridas" pelos alunos com critérios préestabelecidos. Trata-se de um método utilitarista que serve a determinadas teorias e projetos político-econômicos em que a razão neoliberal é determinante. Há um "mercado de habilidades", baseado na teoria do "capital humano", promovido por instituições internacionais como a OCDE e a Unesco (DEL REY, 2009). O discurso das competências parece ser sedutor para trabalhar na evidência de sentido de uma educação supostamente democrática.

Por fim, pensamos o sujeito "autoempreendedor" considerando o que afirmam os autores Dardot e Laval (2009), para os quais há uma junção de enunciados econômicos com enunciados psicológicos. Eles dizem que, da mesma maneira, é pela combinação da concepção psicológica de ser humano, da nova norma econômica da concorrência, da representação do indivíduo como "capital humano", da coesão da organização pela "comunicação", do laço social como "rede", que é pouco a pouco construída esta figura da "empresa de si".

Portanto, o que podemos dizer acerca desta proposta da BNCC, a partir dos recortes analisados, é que ela contém medidas que pretendem mudar o currículo, inserir "competências e habilidades do século XXI" e, assim, "modernizar" a gestão escolar. Num certo sentido, a BNCC dá a base legal para a realização da Reforma do Ensino Médio anunciada pelo MEC e pelo secretário de Educação do Estado de São Paulo, por exemplo, que tem como eixo a flexibilização curricular, o que pode levar a outras "flexibilizações", inclusive no (posto de) trabalho do professor.

Com isso, estamos diante de um efeito de homogeneização na educação brasileira, com uma base nacional comum curricular, que permitirá padronizar e alinhar metodologias, materiais didáticos, formação de professores, etc., o que poderá 
permitir a implantação da avaliação de desempenho do profissional da educação e transformar as escolas (pública e privada) em cursos preparatórios para melhorar o desempenho dos alunos e das instituições escolares nas avaliações externas, sejam elas quais forem: Prova Brasil, SAEB, ENEM e o PISA. Trata-se, para nós, de uma formação discursiva neoliberal, em que a dita crise na educação nacional é apresentada como relacionada a problemas técnicos e desligada dos contextos econômicos, sociais, culturais e políticos. O fracasso escolar, nesta via, é sempre explicado como uma questão "tecnicista" e isto é aliado a um reducionismo no desenvolvimento da aprendizagem simplificado/instrumentalizado no ensino das 'competências' e 'habilidades', o qual se pretende que seja institucionalizado por meio de política pública que, por sua vez, é sobredeterminada pelo mercado-lógico.

\section{Referências}

Base Nacional Comum Curricular: Educação é a base. Terceira versão. Ministério da Educação: Brasil, 2017.

BARTHES, Roland. (1978). Aula: aula inaugural da cadeira de semiologia literária do Colégio da França, pronunciada dia 7 de janeiro de 1977/ Roland Barthes. Tradução de Layla Perrone-Moisés. 15 ed. São Paulo: Cultrix, 2007.

DARDOT, Pierre. e LAVAL, Christian. La Nouvelle Raison du Monde: essai sur la société néolibérale. Paris: La Découverte, 2009.

DEL-REY, Angelique. À l'école des compétences: De l'éducation à la fabrique de l'élève performant. La Découverte, 2009.

GADET, Françoise; PÊCHEUX, Michel. (1981). A língua inatingivel: o discurso na história da lingüística. 2 ed. Tradução de Bethania Mariani e Maria Elizabeth Chaves de Mello. Campinas: Editora RG, 2010.

HUYGHE, F.-R. La Langue de coton, Paris, Laffont, 1991. 
KUENZER, Acacia Zeneida. Trabalho e Escola: a flexibilização do ensino médio no contexto do regime de acumulação flexível. Educ. Soc., Campinas, v. 38, n. 139, p. 331354, Junho 2017. Disponível em: $<$ http://www.scielo.br/scielo.php?script=sci_arttext\&pid=So10173302017000200331\&lng=en\&nrm=iso $>$ Acesso em: 30 Oct. 2017. JORNAL DA UNICAMP - Edição Web. Base Curricular é conservadora, privatizante e ameaça autonomia, avaliam especialistas - Processo de construção da BNCC é marcado por divergências. Seg 04 dez 2017 - ESPECIAL. Disponível em: <http://www.unicamp.br/unicamp/ju/noticias/2017/12/o4/base-curricular-econservadora-privatizante-e-ameaca-autonomia-avaliam>. Acesso em: 20 jul. 2018. LECERCLE, J.-J. Une Philosophie Marxiste du Langage. Actuel Marx, Confrontation. Paris: PUF, Presses Universitaires de France, 2004. MARIANI, Bethania; DIAS, Juciele Pereira. A Leitura na Educação à Distância: Perspectivas e deslocamentos do ponto de vista discursivo. In: SCHERER, Amanda; MEDEIROS, Caciane Souza. OLIVEIRA, Simone (Orgs.). Linguística de nosso tempo: teorias e práticas. Santa Maria: Editora UFSM. 2018.

NOGUEIRA, Luciana. Discurso, Sujeito e Relações de Trabalho na Contemporaneidade. Campinas: Pontes, 2017.

ORLANDI, Eni. Discurso e Argumentação - um observatório do político. Fórum Lingüístico, Fpolis, n.1 (73-81), jul.-dez., 1998.

ORLANDI, Eni. Discurso em Análise: sujeito, sentido, ideologia. Campinas: Pontes, 2012.

ORLANDI, Eni. Formação ou Capacitação? Duas formas de ligar sociedade e conhecimento. In: FERREIRA, E.; ORLANDI, E. (orgs.) Discursos sobre a inclusão. Niterói: Ed. Intertextos. 2014. PÊCHEUX, Michel. [1975]. Semântica e Discurso: uma crítica à afirmação do óbvio. $2^{\underline{a}}$ ed., Campinas: Editora da Unicamp, 1995.

PERROT, M.-D. "Mondialisation du non -sens", dans Recherches, no 20, Paris, La Découverte / MAUSS, 2002. 
PFEIFFER, Claudia Castellanos. Políticas Públicas de Ensino. In: Orlandi, E. (Org.). Discurso e políticas públicas urbanas: a fabricação do consenso. Campinas: Editora RG, 2010. p. 85-100.

SILVA, Mariza Vieira da. Uma Base Nacional Curricular Comum para a leitura nas escolas brasileiras: a política e o político. In: Flores, G. B. et. al (Orgs.). Análise de discurso em rede: cultura e mídia. 1ed. Campinas: Pontes Editora, 2017, v. 3, p. 315-332. SILVA, Mariza Vieira da. Estado, escola, língua: unidades divididas. In: Orlandi, E. et al. (orgs.) Linguagem, instituições e práticas sociais. Pouso Alegre: Univás, 2018. p. 103117.

Recebido em 16/o9/2018.

Aprovado em 26/11/2018. 